\title{
CARETAS, TRAJES Y ESPEJOS: ELEMENTOS DE GROTESQUIZACIÓN EN EL TEATRO DE CHARO GONZÁLEZ CASAS
}

\author{
MASKS, COSTUMES AND MIRRORS: GROTESQUE \\ RESOURCES IN CHARO GONZÁLEZ CASAS PLAYS
}

\author{
Antonia AMO SÁNCHEZ \\ Université d'Avignon (Francia) \\ antonia.amo@gmail.com
}

Resumen: La utilización de recursos estilísticos y códigos sémicos estrechamente relacionados con el trazo grotesco es una de las constantes del teatro de humor de Charo González Casas. La caracterización del personaje mediante la ridiculización indumentaria produce una distanciación irónica, sustentada por dispositivos metateatrales y lingüísticos de diverso orden, que permiten plantear temas metafísicos serios como la muerte desde perspectivas relativizantes. El grotesco opera, pues, como espejo y reflejo de otra manera de ver el mundo.

Abstract: The use of stylistic resources and codes semicos narrowly related to the grotesque outline is one of the constants of the theatre of humor of Charo Gonzalez Casas. The characterization of the character by means of mockery produces an ironic distancing supported by metatheatrical and lin- 
guistic devices of diverse order, which allows it to raise metaphysical topics such as death from a relative prospective. The grotesque operates as a mirror and a reflection of seeing the world in another way.

Palabras clave: Personaje grotesco. Lenguaje escénico. Humor. Muerte.

Key Words: Grotesque characters. Scenic codes. Humor. Death.

«Para encontrar gusto a la vida, no hay como morirse»

Enrique Jardiel Poncela

La máscara, el títere, el pelele o el cuerpo dislocado o afantochado, alimentan estéticamente la historia del arte desde la antigüedad y con frecuencia su semantismo se asocia con el grotesco, considerado como género y como estilo. Las máscaras y los disfraces pertenecen también a un imaginario relacionado con la deformación carnavalesca, la distanciación antimimética, la inversión y la sátira crítica. En cuanto a su relación con el arte dramático del teatro, no sorprende que la crítica considere que es en este canal donde mejor brilla una de las cualidades más destacadas del grotesco, a saber, su teatralidad (Ost, 2004; Astruc, 2010).

En el presente estudio nos centraremos en la caracterización del personaje dramático en el teatro de Charo González Casas a partir de los elementos que ocultan o muestran el cuerpo, al ser éste el instrumento con el que la autora indaga la autenticidad de lo humano. Este enfoque permitirá abordar un tipo de construcción grotesca en la que se combina lo jocoso y lo cínico, el distanciamiento y la identificación, la deformación burlesca y la crítica del conformismo vital, así como del orden establecido. En estas lindes ubicaremos el territorio del grotesco en el teatro de Charo González Casas.

Cabe subrayar igualmente que la impronta grotesca de su teatro es indisociable de la temática de la muerte, obsesivamente presente en el conjunto de su obra, cual interrogación incisiva cuya respuesta resulta siempre insatisfactoria. Un tema, pues, universal y ancestral, tratado por la noble tragedia, distanciado con la comedia, descoyuntado por la mueca de la tragicomedia grotesca, pero nunca manido ni agotado por ser consustancial a nuestra esencia ontológica. 
Nos fijaremos aquí en tres de sus obras más recientes, Corazón al peso (2005), A quien celebre mi muerte (2007) y Ventanilla de patentes (2008) ${ }^{1}$, por ser en ellas donde resalta con brío una escritura dramática de trazo satírico, cuajada de hipérboles, inversiones y humor negro, que permiten la irradiación del grotesco.

\section{HUMOR Y GROTESCO}

Charo González Casas inicia su andadura teatral en los años 80, cuando, gracias a la reescritura de las formas populares del repertorio nacional, se logra resucitar al teatro de autor (proliferaron así etiquetas intertextuales como el neosainete, el neocostumbrismo o el neorrealismo). Se nutre la autora de la tradición del teatro de humor español, desde Tono, Mihura o Jardiel Poncela, sin olvidar la herencia valleinclaniana (Amo Sánchez, 2009; Bueno, 2010). Pero la impronta cinematográfica es también fundamental: los personajes-actores del cine mudo, las comedias de los años 30-50 (Lubitsch, Billy Wilder) o el estilo grouchesco de los hermanos Marx, son otras fuentes de claro alcance en el imaginario de Charo González Casas. A esto se puede añadir, un cierto perfume de ironía y estética kitsch ochenteras, propias de la Movida madrileña, de la que la propia autora fue protagonista e incluso reseñadora en su faceta primera profesional, dedicada al periodismo.

Si nos preguntamos a qué corriente crítica en torno al grotesco podría pertenecer una amplia parte del teatro de Charo González Casas, nos acercaríamos sin duda a las conclusiones contemporáneas que alían lo trágico y lo cómico, el drama y el melodrama, la risa y la mueca patética. Las diferentes teorías sobre el grotesco (las más destacadas y contrastadas son las de Bajtín y Kayser, cuya oposición estriba más en la génesis justificativa del concepto que en la observación de su materia estético-estilística), llegan a similares conclusiones respecto a las definiciones de sus rasgos básicos: deformación, distanciación, humorismo, extrañamiento y cuestionamiento crítico del hombre ante su condición existencial y su realidad social ${ }^{2}$. En la escritura de Charo González Casas emerge de manera exponencial la im-

${ }^{1}$ Ventanilla de patentes (2008) ha sido publicada en su traducción inglesa Patenting Destiny: A tale of two shoes en 2011. En este trabajo citaremos el manuscrito original en castellano, amablemente cedido por la autora.

${ }^{2}$ Respecto a las diferentes teorías y evoluciones del grotesco en la historia de las ideas estéticas y sobre todo respecto a su influencia y arraigo en la literatura dramática española, son de obligada consulta los trabajos de Javier Huerta Calvo (1989, 2003) y de Raquel García Pascual (2006a y 2009). 
pronta carnavalesca bajtiniana, cuyo legado incide en buena parte del teatro de humor español contemporáneo, con la presencia de formas populares expuestas a su vez a las reglas rupturistas del esperpento, el absurdo, lo inverosímil o lo abstracto.

Sin embargo, despunta también en su teatro un halo de dualidad paradójica, de sello kayseriano, que aúna lo hilarante, lo cruel y lo patético. Se establece así una singular relación emotiva con el espectador, quien no adopta una posición meramente pasiva, cual consumidor de un producto ameno e intranscendente, sino que se le conduce sutilmente hacia el terreno de la (auto)crítica en torno a la condición humana, nunca heroica ni engrandecida, sino todo lo contrario. Varias estrategias dramatúrgicas como el metateatro, la ruptura de la cuarta pared, la dislocación lingüístico-paródica y la comicidad de situación, logran vehicular este efecto de implicación crítica distanciada. Pero si el lenguaje verbal es importante, no lo es menos el escénico en la caracterización externa del personaje. Es en esta conjunción de códigos donde la dramaturga consigue cortar patrones de magistral calidad dramatúrgica a la hora de grotesquizar las situaciones dramáticas, y construir con ellas un mensaje crítico.

\section{LAS MÁSCARAS DE LA MUERTE}

Personajes muertos que tratan de asumir su identidad difunta (A quien celebre mi muerte); personajes vivos pero (des)fallecidos existencialmente (Corazón al peso); mujeres al borde del suicidio o del asesinato (Un suicidio es cosa seria); sepultureros que orinan en las tumbas de quienes «se lo merecen» (Brindis); suicidas disuadidos por prostitutas compasivas (Talgo con destino a Murcia), en casi todas las obras de Charo González Casas los vivos parecen estar más muertos que los muertos. Ahora bien, nunca aparece la muerte encarnada o personificada. La dramaturga se concentra en los que la padecen o acaso la disfrutan, las víctimas o los beneficiarios tragicómicos de su guadaña.

Si en Corazón al peso la autora nos rodea de cadáveres autopsiados, de muertes naturales y suicidios compensados por fiestas alocadas y jolgorios descabellados que terminan por devolverle la ilusión al protagonista Edmundo, en A quien celebre mi muerte, asistimos a una mascarada carnavalesca de personajes variopintos, los cuales, hasta que no se les identifica definitivamente como muertos, dan la impresión de salir de una estrambótica fiesta de disfraces, en la que una decadente actriz, una mendiga o un des- 
concertante señor vestido únicamente con una toalla y una pastilla de jabón en la mano, se codean con otros zombis, entre ellos un ejecutado en la silla eléctrica, un hombre con la cabeza abierta u otro hombre con un cuchillo plantado en la espalda. La apariencia de esta galería de personajes presenta ya desde el principio las cualidades de falsificación y simulacro que Philippe Wellnitz (2004: 25) atribuye al grotesco. El simulacro actúa en varios niveles: en el metaliterario, al ser el teatro arte de simulaciones por antonomasia y en el de la ficción interna, por las temáticas sobre el ser y el parecer, el ser o no ser, el estar o no estar muerto... En cuanto a Ventanilla de patentes, los derivativos temáticos en torno a la cuestión del destino, la fatalidad, el azar y la libertad del ser humano, también desembocan en el tema obsesivo de la muerte y de la derrota existencial. En esta comedia disparatada, los personajes evolucionan gracias a unos zapatos mágicos patentados por un inventor chiflado, que tienen el poder de liberar a uno de su destino aciago; también es objeto relevante un catalejo mágico, trasunto de bola de cristal o de espejo maravilloso, que les permite descubrir cuáles hubieran sido las otras caras (o caretas...) de sus destinos.

No obstante, todos estos temas y motivos de raíz mortuoria, no hacen más que enmascarar la verdadera y fundamental problemática que recorre la obra de Charo González Casas, a saber, la vida misma y la posibilidad de vivirla con total libertad, más allá de las ataduras sociales y de los prejuicios morales.

\section{MAMARRACHOS, FANTOCHES Y ESTRAFALARIOS VARIOS: ENTRE TRAJES Y MORTAJAS}

En todas las obras mencionadas se establece un vínculo directo entre el atuendo y el cuestionamiento de la identidad. Del mismo modo, la caracterización de los personajes remite siempre al leit-motiv de la muerte: desde el sastre de Corazón al peso, hasta los protagonistas de A quien celebre mi muerte, ataviados con indumentarias y atrezos relacionados con sus muertes (El matón a sueldo — que aparece con un puñal clavado en la espalda-, El hombre con los sesos al aire, El ejecutado, El novio con su traje-mortaja...), pasando por los personajes de Ventanilla de patentes que retan a sus destinos con frecuencia emparentados con la destrucción y la muerte.

A modo de ejemplo, en Corazón al peso, Edmundo, de profesión forense, se ve obligado a trabajar durante la noche de su propia despedida de soltero al tiempo que trata de ultimar los preparativos de su boda. Decide no 
vestirse con el traje de novio encargado a un sastre profesional, y contrata uno alquilado. Una multitud de personajes, rayanos en lo absurdo, vivos unos y otros muertos, entran y salen incesantemente de la sala de autopsias (recordando ritmos vodevilescos, incluso grouchescos), haciéndole compañía en la víspera de su boda. En esta galería resaltan los aferrados a la importancia del envoltorio social, siendo El Sastre el más representativo:

SASTRE.- (Leyendo la bolsa.) «Arlequín y Colombina, Alquileres de Trajes de Fiesta, Sociedad Limitada»? ;No puedo creerlo!

EDMUNDO.- (Al portero.) Dígale que ya no voy a alquilarlo.

SASTRE.- ¡Un momento! (Sigue leyendo la bolsa.) «Carnavales, chirigotas, mascaradas, simulacros, bodas y puestas de largo»... ¿Significa esto que iba a rechazar mi traje por un disfraz de payaso?

EDMUNDO.- Pues...

SASTRE.- ¿Que iba a subir al altar con un disfraz de fantoche, sudado... y hasta con remiendos? (p. 54).

La caracterización del futuro novio, convertido en un mamarracho (y tratado como tal por su prometida), persigue sin ambigüedades una caricaturización degradante de lo que representa este personaje de personalidad anulada. A pesar de la primera reacción ofendida del sastre, éste se desdice, motivado por un ridículo sentido del destino muy presente en ciertos personajes de Charo González Casas:

SASTRE.- [...], pero a lo mejor resulta que éste es el traje de su vida, oiga. [...] Además, no puede rechazar, sin probárselo, un traje encargado. Eso está muy feo. (Desembala el traje. Caen serpentinas.)

PORTERO.- Si hasta trae confeti. Qué completo...

$[\ldots]$

EDMUNDO.- (Probándose el pantalón.) ¿No le parece que a este pantalón le falta un palmo de largo? La cremallera no cierra. [...] Se ha roto.

SASTRE.- No importa.

EDMUNDO.- ¿Cómo no va a importar que lleve la bragueta abierta?

SASTRE.- El chaqué lo disimula. (Calzándole el chaqué.) El chaqué es al conjunto del traje lo que el corazón al cuerpo. [...] La pieza más emotiva, la que siente y sueña, la pasión, la fuerza, el entusiasmo que pone en funcionamiento todo el conjunto del traje. Camine, camine un poco.

EDMUNDO.- ¿Dónde hay un espejo? (El traje le queda grotesco.) (pp. 55$56)$. 
La culminación de la marionetización de Edmundo marca el momento en el que el personaje empieza a tomar conciencia de su situación, que cambiará rotundamente cuando consiga renunciar definitivamente al traje de novio. El personaje del novio es recurrente en las obras de Charo González Casas. En A quien celebre mi muerte, la entrada de El novio en la insólita sala de espera, donde los demás personajes hacen cola para conocer su juicio final, genera una serie de malentendidos jocosos con tintes de humor negro, que ridiculizan el matrimonio como institución familiar y social:

NOVIO.- Hola.

ESTRELLA DE CINE.- Por fin alguien elegante.

MATÓN A SUELDO.- (Irónico.) A lo mejor es un ángel.

HOMBRE DE LA TOALLA.- ¿Viene usted de alguna fiesta?

HOMBRE CON LOS SESOS AL AIRE.- Vendrá de su propio entierro.

HOMBRE DE LA TOALLA.- Muy bonita, la mortaja.

NOVIO.- (Tristísimo.) Es que es mi traje de novio.

HOMBRE CON LOS SESOS AL AIRE.- ¿Se había casado hace poco?

NOVIO.- No, que me estaba casando.

HOMBRE DE LA TOALLA.- Vaya por Dios.

NOVIO.- El sacerdote me ha dado la extremaunción allí mismo. Qué bochorno, delante de trescientos invitados (pp. 47-48).

El tratamiento expresivo, siempre farsesco, y el trazo grueso carnavalesco se agudizan en ciertas situaciones en las que la alusión al disfraz desenmascara un mundo invertido y alterado cuyo fondo metafórico encaja de lleno con el trasfondo crítico propio del grotesco. Así lo resalta el estudioso Rémi Astruc, citando a Arnold Heidsieck: «el grotesco refiere a un mundo en el que el hombre destruye a su semejante» (2010: 17). Las nociones de alteridad y ruptura definen de lleno la esencia del grotesco contemporáneo que aparece como plasmación de otra visión del mundo. En definitiva, se acomoda aquí la fórmula bajtiniana que define el grotesco no como una mera reseña de la realidad, sino como otra manera de percibir lo real (Astruc, 2010: 11) $)^{3}$.

En Ventanilla de patentes el motivo carnavalesco del mundo al revés y el juego con la otredad estructuran la arquitectura dramatúrgica. La ironía y la comicidad fantástico-grotesca arrasan con la jerarquización lógica en la con-

\footnotetext{
${ }^{3}$ Las traducciones de las obras críticas citadas son nuestras.
} 
cepción de los personajes, vaciados de espesor psicológico y convertidos en estrafalarias marionetas. Resaltan las escenas emparentadas con un teatrillo de títeres en las que aparece y desaparece el doble joven de Alfredo Viejo cual muñeco de trapo («Alfredo viejo suelta el catalejo y Alfredo joven se esfuma como conejo en chistera», p. 17).

Se juega así con un travestismo bipolar por el que el mundo al revés cobra tintes de sinrazón festiva: el hombre pancarta (Alfredo Joven), pobre y marginado, se convertirá en rico magnate planetario (Alfredo Viejo); el preso, se convertirá en «carcelero» y éste en preso..., dando lugar a hilarantes intercambios verbales y situacionales. La inversión de situaciones y/o de estatus social es una constante en el teatro de Charo González Casas, a menudo construido a base de regocijantes transgresiones del orden establecido. Una de las más interesantes aparece en A quien celebre mi muerte, que juega con el trampantojo de la vida para conceptualizar la muerte y viceversa ${ }^{4}$.

\section{ESPEJOS Y REFLEJOS, CARAS Y CARETAS}

Para Rémi Astruc el desdoblamiento, la hibridación y la metamorfosis son las tres figuras por las que el grotesco transmite la alteridad y plasma un trasfondo rupturista que Astruc define, a partir de Camus, como el divorcio entre el hombre y su mundo, entre lo que es y lo que siente (2010: 60). A partir de esta visión, una lectura del grotesco basada en la dualidad, entendida como desdoblamiento y como juego estilístico de contrarios (paradoja, oxímoron, antítesis y contrastes expresivos rayanos en lo absurdo) resulta clave para comprender el sentido grotesco del humor negro con tintes macabros, aunque nunca tenebrosos, que caracteriza la pluma de Charo González Casas.

El dilema existencial subrayado por Rémi Astruc cobra cuerpo en el personaje de Edmundo (cuya fonética onomástica no resulta ajena a esta dimensión simbólica), quien se debate entre dos actitudes opuestas: su vida ordenada de forense concienzudo que comunica más con los cadáveres que autopsia que con su propia novia, o su deseo de libertad y contacto humano auténtico, que conseguirá de la mano de Remedios (como no podía ser de otro modo con tal nombre...), la lúcida prostituta, regalo de su noche de despedida de soltero. La secuencia del espejo es harto relevante del alcance simbólico y ontológico, dado por la crítica al grotesco contemporáneo:

${ }^{4}$ Para ampliar la noción de travestismo vinculado a la estética grotesca remitimos al ensayo de Raquel García Pascual (2009). 
REMEDIOS.- He dicho mi primer cliente, no mi primer amante.

EDMUNDO.- ¿Sabe lo que significa? Que jamás podrá olvidarme. Yo nunca olvidaré mi primer cadáver. Qué impresión me hizo. Estuve a punto de salir corriendo. Pero después, con la práctica, se supera cualquier cosa. Aunque, si le soy sincero, no acabo de acostumbrarme. Anoche mismo soñé que me enviaban un muerto y al levantarle la sábana, resultó que era mi doble. No podía hacerle la autopsia. Se parecía tanto a mí, que me daba pena. Pero luego me di cuenta de que no era mi doble, no. Era yo. ¡Yo! ¿Entiende? No en persona, sino de cuerpo presente. Y a mí mismo, ¿cómo iba a hacerme una autopsia? Así que, para remediarlo, tuve una idea: si me ponía careta, a lo mejor podía hacérsela. Me la puse y en ese instante, el rostro del muerto se transformó en una máscara idéntica a la que yo llevaba puesta. Entonces comprendí: lo que había en la camilla no era un cadáver, sino un espejo. (Pausa.) No tengo vocación. Yo quería poner un bar, con actuaciones los sábados y las vísperas de fiesta (p. 87).

Gracias a la presencia de Remedios, Edmundo consigue romper con su frustrante vida personal y profesional. El proceso de desdoblamiento concretado por el espejo, la «hibridación» a la que el mismo personaje contribuye al introducir el corazón de un cadáver autopsiado en el pecho de su amante suicidada por amor, y, por fin, la metamorfosis físico-indumentaria que opera en Edmundo a lo largo del enredo, hacen de este personaje un ejemplo sólido de los mecanismos grotesquizadores que describe Rémi Astruc para demostrar la relación del grotesco con la búsqueda de una alteridad que invierta el orden del mundo establecido. En la misma tónica Isabelle Ost recupera el enfoque crítico del grotesco defendido por Kayser: «una estructura que implica el fracaso de las categorías que nos orientan en el mundo» (Ost, 2004: 25), denunciando así su estrato monolítico y unívoco.

Asimismo, y a partir de la visión sincrética que Isabelle Ost otorga al grotesco en tanto que oscilación entre elementos opuestos y complementarios, podemos apreciar en esta obra una presencia certera de ambivalencias (no exentas de barniz irónico) que alían lo apolíneo, cuya representación vendría dada por Remedios, y lo dionisíaco, relacionado con las pulsiones destructivas de Edmundo. En esta secuencia con el espejo, se observa bien cómo el cuerpo grotesco y trágico llega a encarnar la desagregación de las formas y el orden reconocibles: «el propio cuerpo deriva hacia el no-ser o se fija en un estatismo mortífero» (Ost, 2004: 36-37). Edmundo, gracias al inconsciente onírico y al espejismo de la muerte, se enfrenta a su imagen anulada, engullido por las presiones sociales. La inversión opera de nuevo en la concepción metafórica del personaje grotesco antiheroico: ya no es él quien «se come» el 
mundo (pantagruélicamente o no), sino la inversa. Esta lectura corre pareja de la que reformula lo trágico en la cultura contemporánea, que ha substituido el poder de los dioses por el de las presiones sociales. En la lucha entre Carnaval y Cuaresma, ésta parece imponerse: el espejo anula a la máscara, devolviendo al personaje a una realidad de angustia y frustración. Pero la lid no es vana, pues Edmundo empieza así el proceso de concienciación que le permitirá librarse (liberarse) de su «cuerpo grotesco», vestido de novio grotesco y ridículo, para «desnudar» su alma y recomponer su vida.

Cabe destacar también, a partir de este ejemplo, el efecto de «inquietante extrañeza» (unheimliche) que se desprende de él, una noción desarrollada por Freud y que abunda en la conceptualización del grotesco como noción constituida de contrastes desestabilizantes. Así se aprecia un substrato de oscilaciones entre la identificación y la distanciación, lo familiar y lo extraño, lo propio y lo ajeno. La relación con el doble y la careta pone de realce una cierta «terribilidad» por cuanto rezuman aquí elementos opresivos y desconcertantes, externos al registro puramente cómico. Ahora bien, es menester matizar el sentido vehiculado por el extrañamiento, que, como bien puntualiza Raquel García Pascual, no debe caer en una desviación léxica que dé a entender una falsa relación con lo espeluznante:

El término originario alemán de «lo inquietante», «lo que provoca sensación de extrañamiento», «la presencia del no-ser», fue traducido como «lo siniestro» [...] cuando Freud se había referido a las apariciones espectrales o las visiones de la muerte como «inquietantes», no espeluznantes (2006a: 44).

Con todo, y como ya habíamos tenido ocasión de constatarlo en otro lugar, a pesar de la omnipresencia de lo macabro (Corazón al peso presenta incluso el subtítulo de "Comedia macabra»), de lo tétrico, lo morboso o lo mortuorio, el tratamiento cómico dado tanto por el lenguaje verbal como por el no verbal invalida cualquier efecto que tenga que ver con lo siniestro o lo infausto (Amo Sánchez, 2009: 10-11). El reflejo especular actúa, pues, como un desdoblamiento por el que el yo se enfrenta consigo mismo. En A quien celebre mi muerte, el juicio final consistirá en la confrontación del difunto con su propio reflejo. Tras franquear la misteriosa puerta por la que se va convocando a todos los personajes (incluso a los espectadores...) ${ }^{5}$, algunos de ellos vuelven a la sala de espera y relatan su experiencia:

${ }^{5}$ En esta obra, el dispositivo metateatral reviste un papel fundamental al final de la obra, implicando de forma directa tanto física como escénicamente al espectador (Amo Sánchez, 2009: 15 y Bueno, 2011: 231). 
MATÓN A SUELDO.- ¿Qué hay detrás de esa puerta?

NOVIO. - Un espejo.

HOMBRE CON LOS SESOS AL AIRE.- ¿Un espejo?

NOVIO.- ¡Sí! Un espejo normal y corriente. Y ahora, déjenme marcharme.

MATÓN A SUELDO.- ¿Tanto misterio para un espejo? Vaya mariconada.

HOMBRE DE LA TOALLA.- Yo creo que está mintiendo.

HOMBRE CON LOS SESOS AL AIRE.- ¡Cállese! ¿Qué ha visto en el espejo?

NOVIO.- Mi reflejo (Intenta escapar.) [...] he cruzado la puerta, me he mirado en el espejo y me he vuelto. Eso es todo.

HOMBRE DE LA TOALLA. ¿ ¿Y cómo sabe que no está muerto?

NOVIO.-Porque al mirarme al espejo lo he visto todo diáfano. ¡Qué claridad, oigan! ¡Deslumbrante!

$[\ldots]$

HOMBRE CON LOS SESOS AL AIRE.- ¿Cómo era su imagen?

NOVIO.- Eso es muy personal. Solamente les diré que me queda muy mal el traje.

HOMBRE DE LA TOALLA.- iSe lo cambio! (Se quita la toalla y se la ofrece mientras el NOVIO destroza el chaqué arrancándole solapas y mangas.) ¿Pero qué hace? ¡Era su traje de novio!

NOVIO.- ¡Pues por eso! ¡Ni boda, ni funeral, ni chaqué, ni mortaja! ¡A la mierda mi novia! (pp. 56-57).

Destrozar el traje de novio (y mortaja), atuendo opresor que califica la posición social y personal, metaforiza la lucha existencial de los personajes que se debaten entre las presiones sociales y el deseo de libertad. Del mismo modo, el juego con el espejo da pie al cuestionamiento de su identidad (vital o mortuoria). Al verse reflejados en un espejo de mano, no ven lo que pensaban poder ver, no se reconocen o incluso lamentan que el espejo no refleje más que un vacío (pp. 58 y ss.). Se funden así las fronteras entre el aquí y el más allá, en una especie de espacio intermedio (como un limbo de almas en pena), en el que se tambalean todas las certitudes. Los mecanismos metateatrales también apuntalan este juego de lo incierto, lo inasible: «HOMBRE CON LOS SESOS AL AIRE.- Que a lo mejor ni existimos. Lo mismo se funden las luces y nos vamos todos a la mierda» (p. 61). Son personajes con cierto trasfondo pirandelliano, en busca de una razón humana válida que justifique y valorice sus vidas y... sus muertes. 
El motivo del espejo aparece también en Ventanilla de patentes como herramienta de desdoblamiento crítico:

(Tras beberse la botella, Alfredo se ha quedado dormido sobre la mesa de su despacho. Entra la señora de la limpieza. Al verlo, se asusta y huye. Alfredo se despierta. Saca un espejo de un cajón y se mira.)

ALFREDO.- Mírate, Alfredo. Hete aquí, convertido en un tonto que parece listo. Eso es el poder, Alfredo, vivir todos los días como si fueran un lunes pero con traje de domingo. Es decir, una mierda. ¿Qué has perdido de tu vida? Te diré lo que has perdido. (Sin soltar el espejo, mira por el catalejo y ve a Alfredo joven retozando con Minerva en el banco.) Los mejores momentos. ¡Ay, Alfredo, Alfredito! Seguiste un destino erróneo [...]. ¿Quién es más miserable, el destino que has burlado o el destino que has seguido? ¿Tu destino verdadero o tu destino falsario? Si hubieras seguido el tuyo, te habrías encontrado. ¡Serías un hombre feliz! No, no puedo seguir mirando. Ya no puedo soportarlo. Ahora soy sólo el voyeur de lo que pude haber sido [...] (p. 24).

El catalejo es una de las variantes formales del espejo. Diseñado también por el inventor (guiño a los personajes locos de las comedias de ciencia-ficción), este objeto permite mirar hacia el pasado y vislumbrar lo que pudo haber sido y no fue, lo cual crea, en ciertos personajes como el magnate Alfredo, un gran desarraigo al constatar que, de haber seguido con su destino apocado y sin pálpito de hombre-pancarta, hubiera, no obstante, conocido la pasión amorosa de la mano de Minerva, también empleada como mujer-pancarta. Las escenas mencionadas en las que Alfredo viejo ve representado ante sí su pasado (con fuerte carga metateatral), están altamente marcadas por una estética kitsch, que incide aún más, si cabe, en el tono caricaturesco global de la obra.

El tratamiento de los temas de la fatalidad, el destino y la felicidad presenta aquí concomitancias con la manera en que la autora aborda el motivo general del misterio de la muerte (y de la vida). Así, pretender saber, racionalizar y controlar los territorios de lo irracional conduce, cuanto menos, a la paradoja de la insatisfacción, a la evidencia de la decepción:

ALFREDO.- [...] La desgracia del hombre no es haber nacido, no, la desgracia del hombre es querer saber y sufrir porque no sabe, isí! pero más desgracia aún es enterarse de todo. Ahora que ya lo sé, sólo sé que lo que quiero es no haber sabido nunca lo que pude haber sido. ;Me cago en estos zapatos! (Se los quita, pero como los lleva atados a los tobillos con cadenas, los arrastra.) ¡Pero más me cago aún en el puto catalejo! (Lo arroja al suelo. 
Se mira al espejo.) Qué hijo de puta es el tiempo. Hay que ver lo que termina haciendo con nosotros (p. 24).

La «carnavalización» de la lengua con el uso de retruécanos, paronomasias, interjecciones y blasfemias, refuerza el efecto grotesco de este monólogo, en el que también opera la tensión entre lo serio y lo vulgar, la temática profunda y la ironía crítica, con fuerte carga intertextual por los guiños calderonianos y shakesperianos.

Por fin, la presencia del espejo, recurrente en la dramaturgia de la autora, denota una consideración particular del efecto especular: mirarse a sí mismo representa la indagación o introspección del hombre consigo mismo, que conduce a la retrospección íntima, al cuestionamiento del pasado y de sus consecuencias en un presente que puede, a su vez, condicionar el futuro. Pero mirar, mirarse y ser mirado alude, por otra parte, a la esencia del juego escénico, especta(o)cular. Así, el escenario aparece en su confín metateatral como ese gran espejo en el que el espectador está obligado a mirarse y a proyectar en él el reflejo de sus propias frustraciones y realidad insatisfecha, probablemente ligada a un inmovilismo conformista como el que atenaza a la mayor parte de los personajes de Charo González Casas. Si el reflejo puede ser sublimado, «fiel», o deforme, en nuestro caso, la geometría especular entre la escena y la sala responde sin duda alguna a aquellas formas cóncavas y convexas que inspiraron en su día a Valle-Inclán. La deformación, la dislocación, la distorsión o la inversión proceden de esta focalización previa que predetermina genérica y estéticamente la postura grotesca en la concepción dramatúrgica de estas obras.

Las figuras relacionadas con la deformación no sólo operan en los mecanismos de implicación con el receptor, en la caracterización de los personajes o en los dispositivos espacio-temporales. También el lenguaje se descoyunta y genera, con su maleabilidad, efectismo grotesco. Distorsionar los clichés lingüísticos, crear asociaciones de frases improbables, romper la lógica de causa-efecto y las expectativas del interlocutor (y del receptor), etc., forma parte del proceso creador expuesto al espejo grotesco, en el que no sólo se dinamitan las estructuras sociales, la episteme o el ethos, sino también los canales de comunicación elemental basados en el lenguaje. Lourdes Bueno aborda con rigor las diferentes técnicas utilizadas por Charo González Casas a la hora de trabajar linguísticamente el humor: «ruptura de fraseologismos, [...] utilizar expresiones y palabras que, bien por estar fuera de su contexto bien por adaptarse de forma irónica a éste, crean una atmósfera hilarante» (2010: 228 y ss.). Estos mecanismos lingüísticos son recurrentes en la expresividad de los 
personajes; y a falta de profundidad psicológica, es lo que los define en tanto que entes de ficción. La teorización de Isabelle Ost, apropiándose los términos de Pirandello, es cuanto menos clarividente a este respecto:

La derrota del lenguaje, ridículo y trágico al tiempo, es sinónima de grotesco, es síntoma de la desmultiplicación hasta el infinito de los mismos personajes declamando las mismas frases. Se trata de un funcionamiento especular infinito, de una sucesión sin fin de espejos: arrancamos una máscara y nos topamos con otra, sin poder descubrir nunca el verdadero rostro de la gente y de las cosas (2004: 25).

Habida cuenta de lo dicho hasta ahora, las formas especulares definen una de las singularidades mayores de la escritura grotesca, constituida de conglomerados sémicos diversos, convergentes en el mismo juego desconcertante de la máscara infinita con la que poder alcanzar el centro de la gruta: las cavidades más profundas del ser humano.

En las obras estudiadas, los contrastes especulares (concretados en trajes nobles frente a trajes afantochados o en el desdoblamiento de los personajes), las inversiones de situaciones (boda-farsa), las inverosimilitudes cómicas (fiesta de despedida en una sala de autopsias), el lenguaje dislocado, etc., contribuyen a generar un mundo paralelo al de la realidad banal y codificada, expuesta al azote burlesco de la autora. Los esquemas sociales establecidos (despedida de soltero, boda, compromiso «de por vida», trabajo, familia, poder, etc.) resultan así maltrechos por la deformación grotesca.

El cruce tragicómico es, pues, el lugar en el que aparece la mueca patética que define una buena parte de la dramaturgia de Charo González Casas. Una dramaturgia constituida de contrarios, paradojas y ambivalencias en las que la figura de la antítesis parece quedar anulada por una fuerza superior gracias a la cual los opuestos conviven y hasta se avienen (la vida, la muerte; el misterio y la desacralización; la máscara y el rostro; el yo y el otro; la realidad y la ficción, el ser y el parecer). Esa fuerza procede sin duda de la escritura de la autora, de su capacidad por (re)crear nuestro «sentido grotesco de la vida».

\section{REFERENCIAS BIBLIOGRÁFICAS}

AMO SÁNCHEZ, A. (2001). «La carne y el carnaval en dos obras barrocas de José Luis Alonso de Santos». En Corps en scènes, Roswita/Monique Martinez Thomas (eds.), 23-30. Carnières: Lansman. 
- (2009). «A quien celebre mi muerte de Charo González Casas: el humor a vueltas con la muerte». Estreno 35, 7-17.

ASTRUC, R. (2010). Le renouveau du grotesque dans le roman du XXe siècle. Paris: Garnier.

BAJTÍN, M. (1988). L'Oeuvre de François Rabelais et la culture populaire au Moyen Age et sous la Renaissance. Paris: Gallimard, col. TEL [1970]. (Edición original rusa de 1965).

BUENO, L. (2010). «A quien celebre mi muerte, de Charo González Casas: la ironía de estar muerto y sentirse vivo». En El teatro de humor en los inicios del siglo XXI, José Romera Castillo (ed.), 223-232. Madrid: Visor Libros.

GARCÍA PASCUAL, R. (2006a). Formas e imágenes grotescas en el teatro español contemporáneo. Madrid: Fundación Universitaria Española.

- (2006b). «Lo grotesco en el teatro breve de los autores de tendencia neorrealista y neovanguardista». Cuadernos del Ateneo 21, 23-38.

- (2009). «Travestismo y destape del tabú: el teatro de Luis Riaza». Foro Hispánico: Revista Hispánica de Flandes y Holanda 34, 279-299.

GONZÁLEZ CASAS, Ch. (2005). Corazón al peso. Alcalá de Henares: Teatro Independiente Alcalaíno.

- (2007). A quien celebre mi muerte. Alcalá de Henares: Teatro Independiente Alcalaíno.

- (2010). Patenting destiny: A tale of two shoes. En Estreno Contemporary Spanish Plays 33, Iride Lamartina-Lens y Susan Berardini (eds.). Traducción de Patricia W. O’Connor (Versión original, Ventanilla de patentes, 2008, en prensa).

HUERTA CALVO, J. (coord.) (1989). Formas carnavalescas en el arte y en la literatura. Barcelona: Serbal.

- (2003) (ed.) Historia del teatro español, 2 vols. Madrid: Gredos.

KAYSER, W. (1964). Lo grotesco. Su configuración en pintura y literatura. Buenos Aires: Nova.

OST, I.; PIRET, P. y VAN EYNDE, L. (eds.) (2004). Le grotesque. Théorie, généalogie, figures. Bruselas: Publications des Facultés Universitaires Saint-Louis. 
OST, I. (2004). «Le jeu du grotesque ou le miroir brisé». En Le grotesque. Théorie, généalogie, figures, Isabelle Ost et alii (eds.), 29-42. Bruselas: Publications des Facultés Universitaires Saint-Louis.

ROMERA CASTILLO, J. (ed.) (2010). El teatro de humor en los inicios del siglo XXI. Madrid: Visor Libros.

VASSEROT, Ch. / ROSWITA. (ed.) (2002). Le corps grotesque. Carnières: Lansman.

WELLNITZ, Ph. (2004). «Le grotesque littéraire — simple style ou genre à part entière?». En Le grotesque. Théorie, généalogie, figures, Isabelle Ost et alii (eds.), 15-27. Bruselas: Publications des Facultés Universitaires Saint-Louis. 